Alfio Mastropaolo. Catedrático de Ciencia de la Política de la Università degli Studi di Torino. Enseña Democracia y Participación Política y Democracias Modernas en el Dipartamento de Culture, Politica e Società. Se ha interesado mucho por el fenómeno de la antipolítica y de las aporías de la democracia. Dentro de sus publicaciones, se encuentran: Il parlamento. Le assemblee legislative nelle assemblee contemporanee (2006), Laterza, con Luca Verzichelli; La democrazia è una causa persa? Paradossi di un'invenzione imperfetta, 2011, Bollati Boringhieri.

Contacto: info.mastropaolo@unito.it 


\section{LA COMPETENCIA LEGÍTIMA PARA EL MONOPOLIO ESTATAL}

Alfio Mastropaolo

Università degli Studi di Torino

\section{THE LEGITIMATE COMPETITION FOR THE GOVERNMENT MONOPOLY}

DOI: $1017450 / 160104$

Fecha de recepción 29 de febrero de 2015; fecha de aceptación 27 de abril de 2016. El presente artículo se ha escrito en el marco del proyecto de investigación desarrollado en el Dipartimento di Cultura, Politica e Società, Università di Torino.

\section{Resumen}

A despecho de su práctica, el cuento maravilloso del régimen representativo hoy día es tan omnipotente como para que valga la pena contradecirlo. Despojándola de la retórica con la que se legitima, el autor analiza la naturaleza de la técnica de gobierno y de la forma de dominio que minimiza la coerción. De ahí que sobresalga una trama compuesta por oscilaciones entre la síntesis política de la acción de gobierno y la recomposición del pluralismo.

\section{Palabras clave}

Régimen, dominio, pluralismo, intereses, contingencia 


\section{Abstract}

The enchanted narration of representative regimes, despite their practice, today is so omnipotent that contradicting it is worthwhile. Deleting the rhetoric with which they legitimate themselves, the author shows the nature of government technique and dominion form that minimizes coercion. What comes to surface is a weave made of oscillations: between political synthesis of government action and recomposition of pluralism.

\section{Key words}

Regime, dominion, pluralism, interests, contingency

\section{Cómo nació el régimen representativo}

Este ensayo no cuenta una nueva historia. Con mayor humildad, vuelve a leer y a interpretar una historia antigua. Vuelve a contar qué es un régimen representativo, despojándolo de la retórica mágica por la que está caracterizado. No es un intento original. El pensamiento conservador siempre lo ha interpretado de esa manera. Sin embargo, a despecho de su práctica, el cuento maravilloso del régimen representativo hoy día es tan omnipresente como para que valga la pena contradecirlo otra vez. En resumen, el régimen representativo y el democrático no son una de las formas de atribuir el poder a los gobernados -por ejemplo, eligiendo a los gobernantes-, sino más bien una técnica de gobierno, que sirve para reducir los costes de la acción de gobierno, minimizando la coerción y granjeándose el ascenso de los gobernados.

Anticipa ese tema una frase contenida en un famoso libro de Norbert Elias. Siguiendo las huellas de Weber, en ese libro Elias afirma que lo que llamamos Estado moderno es un efecto colateral e indeseado de la lucha por el monopolio del poder que tuvo lugar a finales de la Edad Media. Para Elias, ninguno de los State builders quería construir el Estado. Más bien, eran las facciones las que abrigaban ambiciones de dominio. Sin embargo y de forma inesperada, por una extraña serie de circunstancias, el proceso de acumulación y concentración de medios de coerción llevado a cabo -pasando por hazañas militares, alianzas matrimoniales y coaliciones de todo tipo- por las grandes potencias dinásticas dio lugar a una nueva forma de organización del poder basada en 
las monarquías absolutistas y en sus aparatos burocráticos: el Estado. Según Elias, entre los siglos XVII y XIX, la lucha por el monopolio siguió otro rumbo. Cuando se estableció el monopolio estatal, sus pretendientes se multiplicaron y entre ellos prevaleció la idea de disputárselo pacíficamente, junto con los beneficios correspondientes. Desde aquel entonces, las luchas para administrar el monopolio, reglamentadas por el aparato monopolístico, controladas por el monopolio mismo, tomaron la delantera, llevando al nacimiento de lo que, para Elias, solemos llamar régimen democrático. ${ }^{1}$

Despojados de la maravillosa retórica de la que se envuelven y con la que se legitiman, los modernos regímenes representativos y democráticos antes que todo serían esto: una forma de Estado, pues una forma de dominio, por cuyos papeles de mando se puede competir. Esa definición podrá parecer restrictiva e irrespetuosa. Seguramente en los regímenes representativo-democráticos haya algo más. Están la libertad de pensamiento y de opinión, la de asociación, de afiliarse a partidos y sindicatos, de declarar la huelga. También hay un generoso ideal de convivencia, libre e igualitaria. Sin embargo, si entre los siglos XVII y XVIII, gracias a una pluralidad de factores como la educación, la prensa y el aumento de las comunicaciones, apareció una nueva facción, o una constelación de facciones que empezaron a formular esos valores, y cuyas armas eran la razón, la ciencia y la discusión, dudamos de que a solas, con esas armas, ellas lograrían instalar las modernas instituciones y alcanzar el reconocimiento del derecho como el medio que contribuyera oficialmente al ejercicio de la autoridad estatal. Habermas ha llamado esta constelación de facciones esfera pública, ${ }^{2}$ pero también se puede hablar de "tribunal de la opinión", donde se unían intereses privados ya con la suficiente fuerza como para llevar a puntos de vista críticos capaces de condicionar el ejercicio del monopolio. ${ }^{3}$ Sin embargo, para que el moderno régimen representativo naciera no solo fueron suficientes las gacetas, los libros, los panfletos, a través de los cuales el tribunal de la opinión tomaba sus decisiones. Era necesario que las facciones organizadas, que competían por el monopolio estatal, empleando armas mucho más temibles, como la violencia y la riqueza, se pusieran de acuerdo en ejercerlo de forma conjunta, otorgándose recíprocamente las necesarias garantías, como la fijación de límites a la acción del Estado. Fue una revolución. La violencia no desapareció total y definitivamente como

1. N. Elias, Über den Prozess der Zivilisation: soziogenetische und psychogenetische Untersuchungen (1939), Suhrkamp, Frankfurt am Main, 2000.

2. J. Habermas, Strukturwandel der Öffentlichkeit: Untersuchungen zu einer Kategorie der bürgerlichen Gesellschaft, Suhrkamp, Frankfurt a. M., 1962.

3. K. M. Baker, "Politique et opinion publique sous l'Ancien Régime”, en Annales. Économies, Sociétés, Civilisations", 1, XLII, 1987, pp. 41-71. 
técnica para acceder al Gobierno, sino que introdujo una nueva que, en Occidente, se convirtió en regla, haciendo de la violencia una excepción.

Inglaterra fue la patria de esa invención, donde la guerra civil fue provocada por la negativa del rey a llegar a un acuerdo con sus opositores. La dictadura de Cromwell -que fue la primera dictadura moderna- coincidió con la posibilidad, provisional para una de las facciones vencedoras -el ejército-, de someter a todas las demás. Esto duró hasta cuando, tras la muerte de Cromwell, las últimas facciones se dieron cuenta de que ninguna de ellas podría superar de forma duradera a las demás, que convenía negociar. Empleando las instituciones existentes, los notables del país reunidos en el Parlamento decidieron que era mejor manejar de forma colegial el capital estatal. Para este fin, ellos transfirieron la soberanía del rey al Parlamento, del que llevaban formando parte desde hace siglos, desatendiendo el pedido de otros que querían otorgarla directamente al pueblo. ${ }^{4}$

Si en Inglaterra fue tormentoso, en Francia, en Alemania y en muchos otros países el acuerdo sobre la dirección compartida del monopolio estatal lo fue mucho más, sobre todo cuando algunas facciones poseían recursos militares. De todas formas, con el paso del tiempo, las partes coincidieron en considerar al Parlamento como el lugar fundamental en el que se administraría el capital estatal y a las elecciones como el medio para acceder a este. Cíclicamente, por medio de las elecciones -y de forma continuada- en el Parlamento y en el escenario público, al pluralismo de los intereses y de los valores -que es más o menos lo mismo- se les otorgaba la posibilidad de poner en discusión la acción del Gobierno e incluso el orden establecido por el Estado, a condición de respetar algunas reglas formales y substanciales. Desde aquel entonces, los conflictos se tratarían traduciendo en números las relaciones de fuerza, a través de la alternancia de los elegidos tras las elecciones de los electores, y tomando decisiones por mayoría. No acabarían el conflicto y el desorden, sino solo sus manifestaciones más radicales.

Es más: el Estado y la política moderna nacieron en el desorden y del desorden, sacándole orden. Después de haber intentado reprimir toda nueva manifestación de desorden, se inocularon una vacuna para reconocer el desorden, para gobernarlo, apaciguarlo y convivir con este. No todas las manifestaciones de desorden fueron toleradas. Sin embargo, el régimen representativo es una técnica de gobierno en virtud de la cual -para minimizar la coerción- una dosis controlada de desorden y de conflicto se apodera oficialmente de los responsables del orden estatal, pensando reconstruir de esa

4. Mejor dicho, en el King in Parliament, es decir, en el rey, en la Cámara de los Lores y en la de los Comunes de forma conjunta. 
manera -adaptándolo a las circunstancias y a los intereses en juego y legitimando esta técnica- el antiguo ideal del autogobierno. ${ }^{5}$

Recurrir a las elecciones para elegir a los gobernantes no fue casual. Las elecciones no eran algo novedoso. Son una institución ultramilenaria. Ya habían sido experimentadas por los gobiernos ciudadanos en los que, una vez proclamada la soberanía popular, se solían gestionar de forma colegiada los asuntos públicos. La Iglesia romana llevaba recurriendo a las elecciones desde hace mucho tiempo, así como el Sacro romano imperio germánico, desde el siglo XIV. En ambos casos, el cargo era vitalicio y el colegio electoral muy reducido, mientras que en las repúblicas ciudadanas -en las que votaba el pueblo- los cargos electivos se renovaban de forma periódica. Entonces, puesto que la soberanía se estaba poniendo en las manos del pueblo, ¿por qué no se empleó una técnica más igualitaria como el sorteo? También esta técnica se empleaba, por ejemplo, en las repúblicas ciudadanas. Tal vez la solución elegida aclare cuáles eran las reales intenciones de quien la adoptó.

Según Bernard Manin, las elecciones logran -por lo menos de vez en cuando- realizar la voluntad del pueblo, ${ }^{6}$ aunque quepa subrayar otra calidad, tal vez más importante, para quien ya posee el poder y quiere limitar el desorden. El margen de imprevisibilidad de las elecciones es mucho más limitado que el del sorteo, que es ciego y de peligrosa igualdad. Las elecciones pueden ser condicionadas y manipuladas y, por lo general, sus resultados son previsibles. Además, Manin añade que las elecciones se presentan como un dispositivo aristocrático que premia a quien tiene más recursos económicos y relacionales que los demás. Esto es, sirven para confirmar las élites ya existentes.

Solo más tarde se llegó a la competición, a la alternancia mesurada del poder entre partes políticas y a la contraposición entre mayorías y minorías. Pues, no formaban parte de la idea originaria del régimen representativo, ${ }^{7}$ que al principio contaba los votos, pero que no quería entregarse por completo a ellos. Los inventores de este régimen creían que la representación seleccionaría a las clases dirigentes "naturales”, a las figuras más destacadas de cada comunidad local, que se encargarían de los problemas colectivos de forma conjunta. Sin embargo, si esto ocurrió al principio, con el paso del tiempo esa preeminencia fue erosionada. Por ejemplo, Montesquieu -quien en las páginas del Espíritu de las leyes hablaba de la separación de los poderes como ejemplo-

5. G. Poggi, Varieties of Political Experience, Ecpr Press, Colchester, 2014, pp. 43-51.

6. Eso es lo que sugiere B. Manin, Principes dugouvernement représentatif, Flammarion, Paris, 1996, quien reconstruye también detalladamente cómo se ha impuesto el principio electoral.

7. P. Rosanvallon, Democratic Legitimacy: Impartiality, Reflexivity, Proximity (2008), Princeton University Press, Princeton-Oxford, 2011, en particular pp. 53-59. 
criticó enseguida la litigiosidad y el particularismo excesivos de la política inglesa. ${ }^{8}$ Para evitar este riesgo y que la contienda política se fundamentara en la capacidad de los que aspiraban a la representación de granjearse a los electores, permitiendo que los intereses particulares destrozaran el poder legislativo, en 1789 Sieyès decidió que este último fuera un conjunto unitario e indivisible, con intereses acordes que lo transformarían en una autoridad monocrática.

En la monarquía absoluta, el poder del rey encabezaba una sociedad ordenada jerárquicamente, en la que la pluralidad era reprimida o sometida, mientras el conflicto estaba oficialmente prohibido. Era un fantasma que, desde aquel entonces, siguió cerniéndose sobre los regímenes representativos que si, por una parte, toleraban la existencia de disputas por el poder, como el desorden y el conflicto, esperando solucionarlos, por otra parte, nunca lo lograron en su totalidad. Por lo tanto, nunca fueron plena y definitivamente aceptados por todos, y esta fallida aceptación siguió siendo para ellos un motivo de debilidad. Para algunos el pluralismo y la competencia siempre han sido inadmisibles y había que eliminarlos; para otros, había demasiada competencia y era necesario limitarla. El pluralismo, el contraste y el desorden controlados que los regímenes representativo-democráticos legitimaban siempre han sido el blanco de disputa política, haciendo cada vez más hincapié en el perjuicio que ellos proporcionaban a la moralidad pública, al bien común, a la unidad del cuerpo colectivo, a la eficacia de gobierno, etcétera.

Desde aquel entonces, la historia de los regímenes representativos está caracterizada por oscilaciones que, de manera periódica, aumentan o disminuyen las oportunidades que el desorden tiene de entrar en el Estado. Aumentan simbólicamente y disminuyen materialmente y viceversa. Hay que observar este movimiento tanto desde el punto de vista de los gobernados como de los gobernantes. El régimen representativo huele a mofa tras sus promesas no mantenidas. Sin embargo, a quien ejerce la autoridad del Estado, sean las que sean sus motivaciones, siempre se le presenta el problema de la eficacia de la acción de gobierno, es decir, de cómo llegar a una síntesis política frente a un pluralismo rebosante. Representar y gobernar significa elegir entre acciones diferentes, darles un significado diferente a los intereses. Los criterios empleados para ordenarlos nunca son unívocos y siempre se ponen en tela de juicio.

En realidad, incluso la autoridad monocrática, que solo es un modelo abtracto, tenía el mismo problema. Ningún soberano, ni siquiera el más poderoso, ha podido nunca

8. K. M. Baker, "Politique et opinion publique sous l'Ancien Régime”, en Annales. Économies, Sociétés, Civilisations, 42, 1, 1987, pp. 41-71. 
elegir a solas o ha sido exonerado de pedidos, condicionamientos, presiones, negociaciones, compromisos. Si la nostalgia de la autoridad monocrática ha seguido existiendo es porque algunos intereses han intentado imponerse sobre otros. En su forma más extrema, siguió siendo el motivo de miles de antiparlamentarismos y antipartidismos nacidos con el régimen representativo.

Aunque a menudo se consideren parecidos, el pluralismo político no tiene nada que ver con el pluralismo de mercado. Y eso que, cuando nació el régimen representativo gracias a las tres grandes revoluciones "burguesas", se estaba desarrollando una revolución cultural -por la que se ha interesado A. O. Hirschman- que reconocía y consideraba virtuosos los intereses y su pluralidad, aunque los enfrentara a las pasiones, subrayando la negatividad y la irracionalidad de estas. ${ }^{9}$ Sin embargo, mirándolo bien, las que se llamaban pasiones no eran otra cosa que los intereses por la política, llamados así precisamente para desacreditarlos. Viceversa, se llamaba interés -y se consideraba pacífica y racional- la pasión por la riqueza.

Asimismo hay una correspondencia evidente entre el concepto foucaultiano de seguridad y la facultad que el régimen representativo otorgó a los intereses y a las opiniones de superar el perímetro de la política para manejar de forma conjunta o contensiva el monopolio estatal. Esto es, también el régimen representativo preveía reglas dentro de las cuales -solo dentro de las cuales- los protagonistas podían moverse con libertad. Sin embargo, esas reglas eran cada vez más apremiantes que las adoptadas para la economía. La vacuna pluralística podía tomarse de forma que no alterara la unidad y la acción del Estado, en defensa de lo que este consagraba como orden. También está claro que la dosificación de la vacuna, las garantías recíprocas entre las partes políticas y las modalidades de contención de la pluralidad y del desorden fueron el blanco de grandes disputas, con la misma promesa de reconstruir de manera más adecuada la pluralidad dentro de una autoridad unitaria, entregada al orden y al interés general.

Lo que cabe destacar es que las reglas dirigidas a contingentar y reconstruir el pluralismo y la competencia política -tal y como les ocurre también a las reglas de competencia del mercado- nunca han sido dictadas por un legislador ajeno al juego, sino más bien partícipe y fruto del juego. Las que negocian y establecen las reglas, tanto las electorales como las constitucionales, que atañen a la, en cierta medida, delicada cuestión del desplazamiento de los poderes dentro del Estado -Elias lo subraya en su definición- son las facciones de momento vencedoras, que se hallan en la doble

9. A. O. Hirschman, The Passions and the Interests: Political Arguments For Capitalism Before Its Triumph, Princeton University Press, Princeton (NJ), 1977. 
condición de establecerlas y de influir en el juego. Inevitablemente, ellas dictarán reglas convenientes, útiles también a los recursos de poder de los que disponen de momento. Similar duplicidad persiste. Incluso puede ser que las reglas sean dictadas por una convergencia inestable de facciones, en una situación similar a la del "velo de ignorancia”. Las heterogéneas y precarias coaliciones que escribieron la Constitución francesa de 1946 y la italiana de 1948 llevaron a constituciones "garantistas" y a leyes electorales proporcionales. Ninguna parte política pudo escribirlas en su provecho exclusivo. En cambio, la Constitución francesa de 1958 y la consiguiente ley electoral fueron escritas por una parte política que había tomado la delantera.

\section{Contingentar el pluralismo}

Las constituciones son las reglas más importantes con las que el desorden se contingenta, y con las que las partes políticas se protegen recíprocamente. Por lo general, las constituciones se presentan como el mito fundador del cuerpo político. La solemnidad que caracteriza su aprobación ataja sus eventuales cambios, porque sería simbólica y políticamente perjudicial incluso para quien tuviera la valentía de hacerlo. Sin embargo, las constituciones son arquitecturas de reglas y de principios que aparecen en determinados períodos históricos, y que están sometidas a sus cambios, pues están a la merced de la lucha por el poder. Las constituciones son programas políticos alrededor de los cuales hierve un incesante ajetreo, secreto y patente, de interpretación, de acuerdo, de adaptación, de revisión, caracterizado por discursos dirigidos a justificar inclusiones y exclusiones, además de saberes que elaboran las argumentaciones necesarias para eso. La suerte de las constituciones, es decir, su práctica, está sometida a la lucha que se desarrolla entre las instituciones del Estado, y entre ellas y las facciones que luchan por el capital estatal. ${ }^{10}$

De ahí que haya poderes del Estado y cuotas de capital estatal sometidos al pluralismo y otros inmunizados. El pluralismo puede entrar, con los debidos frenos, en parlamento, se limita al ejecutivo, está excluido de la burocracia y de la magistratura. Puede meterse en estas de forma extraoficial y no autorizada, pero no de forma oficial, por ser lugares de gobierno muy resguardados. Establecer los confines entre los diferentes poderes y,

10. Tal vez sea democráticamente más coherente que cada generación escriba su constitución. ¿Por qué las generaciones actuales deberían obligar a las venideras? Si la democracia fuera coherente con sus promesas -y no lo es-, tal vez sería necesario programar su revisión periódica. Trata ese tema P. Rosanvallon, Democratic Legitimacy . 
sobre todo, las modalidades con las que arbitrar eventuales conflictos atañe a la acción del Estado. Al principio, las constituciones identificaban al Parlamento como el locus fundamental de la acción del Gobierno. Luego, con la práctica y con la revisión de las normas, el Parlamento ya no logró contener el pluralismo y los partidos se convirtieron en el baricentro del Gobierno mismo. Al considerar su pluralismo excesivo, fue entregado al ejecutivo. Finalmente, una parte importante de los poderes de gobierno fue entregada a los particulares, a los técnicos y a las autoridades independientes, en Europa a Bruselas y a Fráncfort.

Otra controversia particularmente fuerte que intenta reglamentar el pluralismo atañe a la definición del pueblo soberano. ¿Quién lo compone? ¿En la base de cuáles títulos puede ejercer la soberanía que se le reconoce? ¿Quién es el titular del derecho de voto? Por mucho tiempo la delimitación se ha basado en límites de censo, de capacidad, de género, pero también religiosos. En los albores del régimen representativo, el gran teórico de la tolerancia, Locke, justificó la exclusión de los católicos, culpándoles de fidelidad a un soberano extranjero. Tardaron casi un siglo antes de que les reconocieran el derecho de voto. Por lo que a las barreras de censo se refiere, también los revolucionarios americanos y franceses establecieron las propias. Cuando acabó la revolución, Benjamin Constant dijo que el derecho de voto se tenía que destinar a los que tuvieran intereses -propietarios- para salvaguardar. ${ }^{11}$ En cambio, a pesar de apoyar el sufragio universal, e incluso el voto a las mujeres, atribuyendo a la participación democrática la capacidad de educar a los ciudadanos, en la Inglaterra victoriana John Stuart Mill sugirió que -para no correr demasiados peligros- se atribuyera el voto múltiple a la minoría de las clases cultas. ${ }^{12}$ Como es sabido, el voto a las mujeres se dispuso más o menos bien entrado el siglo XX. En la muy democrática Suiza esto ocurrió en 1971.

Además del electorado activo, también el pasivo se puede delimitar. A pesar de reconocer la igualdad en los derechos políticos, los regímenes representativos y democráticos distinguen entre intereses, conflictos, competidores legítimos e ilegítimos. ${ }^{13} \mathrm{~A}$ partir de la posguerra, en Italia ya no hubo la posibilidad de volver a crear el partido fascista. En los primeros años cincuenta se intentó vedar el Partido Comunista. Eso había ocurrido en la mayoría de la Europa exsocialista. ${ }^{14}$ En el pasado también fue circunscrita la lucha política, limitándola al Parlamento, a las elecciones y a los debates de la esfera

11. B. Constant, Principes de politique (1815), en Id, De la liberté cbez: les moderncs. Ecrits politiques, Paris, Librairie Générale Française, 1980, pp. 316-317.

12. J. S. Mill, Considerations on Representative Government, Parker son and Bourn, 1861.

13. E. Neveu, Sociologie politique des problèmes publics, La Découverte, Paris, 2015, p. 76.

14. P. Bourdieu, Sur l'État. Cours au Collège de France (1989-1992), Seuil/Raisons d'agir, Paris, 2012, p. 227. 
pública. Tuvimos que esperar hasta la segunda mitad del siglo XIX para que la política pudiera ejercerse de manera pacífica en las plazas. Tampoco al enfrentamiento político televisivo se llegó con facilidad.

También hay maneras más simples para seleccionar a los competidores, así como el ejercicio del derecho de voto se puede limitar de muchos modos. Apenas se establezca quién tiene el derecho de votar, cabe decidir las reglas de la competición, las modalidades de voto e incluso cómo contar los votos mismos. La historia de las elecciones está caracterizada por miles de normas formales e informales que reglamentan concretamente el acceso al voto y a la competición electoral, y que presiden el desarrollo de la competición. No hay normativas electorales que no causen agravios a algunos o que no favorezcan a otros. Los resultados electorales se pueden supeditar, tal y como nos enseña la experiencia estadounidense, transformando las circunscripciones. En Estados Unidos, el gerrymandering es una costumbre. Sobre todo en los Estados republicanos, las circunscripciones de prevalencia democrática se disuelven en el cruce con las republicanas. Algo similar se puso en práctica en Europa a escala continental: la sutil propensión de los electores de la Europa Occidental para los partidos de izquierda fue neutralizada, cruzándola con la evidente preferencia por la derecha de los electores de la ex-Europa socialista.

También el secreto del voto, el tipo de papeleta electoral, la personalización o la despersonalización de las candidaturas sirven para seleccionar o prohibir. ${ }^{15}$ Las reglas pueden impulsar o frenar selectivamente la participación, con consecuencias diferentes para las fuerzas políticas y los intereses que representan. Pretender -tal y como ocurre en Francia-que los electores se inscriban en las listas electorales desanima a los electores menos instruidos y más reacios a la burocracia. ${ }^{16}$ Desde hace algunas décadas, el abstencionismo ha aumentado por doquier y caracteriza, sobre todo, a las clases más débiles. Si no se intenta ponerle remedio -tal y como hacen de momento las partes políticas- se corre el riesgo de confirmar una exclusión y de favorecer algunas manifestaciones del pluralismo a despecho de otras.

Otro medio para seleccionar a los competidores y para condicionar los resultados son los recursos financieros, que quien lleva la voz cantante puede manipular. Las partes políticas que ya gestionan las finanzas públicas, y que también promocionan las policies, gozan de ventajas mayores con respecto a sus competidores. De todas formas, incluso

15. Por lo que a las técnicas de voto y por cómo estas condicionan a los electores se refiere, cfr. A. Garrigou, Le vote et la vertu. Comment les français sont devenusélecteurs, Presses de la Fondation Nationale des Sciences Politiques, Paris, 1992. 16. Un oculto límite de censo es la educación. Los que tienen menor instrucción están menos predispuestos a votar: D. Gaxie, Le cens caché. Inégalités culturelles et sé-grégation politique, Seuil, Paris, 1978. 
cuando el Estado se hace cargo de la financiación de la competición pública, sin ninguna restricción, los competidores established son favorecidos respecto de los outsiders. Más allá de las financiaciones ilegales, la legislación -más o menos permisiva- relativa a la financiación privada de las campañas electorales proporciona ventajas diferentes, dependiendo del estatus de los competidores.

Otro punto fundamental son los criterios por medio de los cuales se cuentan los sufragios. Los regímenes representativos afirman que a cada hombre corresponde un voto. La modernidad no hace otra cosa sino rendir homenaje a los números. Sin embargo, el valor del voto puede variar mucho. Las leyes electorales proporcionales atribuyen más o menos el mismo valor al voto de cada cual. Las leyes mayoritarias construyen sus mayorías a partir de minorías electorales. Las barreras electorales borran algunos votos: no muchos, pero algunos sí. Además, es bien sabido que los regímenes proporcionales promocionan la participación electoral más que aquellos mayoritarios. Ninguna de esas variantes es secundaria.

De ahí que los partidos del poder en los regímenes representativo-democráticos se jueguen con cartas distribuidas por los jugadores más fuertes, que incluso las alteran. El hecho de que esos partidos sean libres y honestos solo es el principio en la base del cual se legitiman, pero se trata de una libertad y de una honestidad condicionadas. No hay contienda electoral que no esconda algún artificio. Por lo contrario, lo bello de los regímenes representativo-democráticos es que, de vez en cuando, esconden algunas sorpresas. Por mucho que se quiera limitar su carácter imprevisible, se han dado resultados electorales inesperados con outsiders no gratos. A pesar de todas las astucias de los que escriben las reglas para tutelarse, la cíclica repetición de la contienda electoral ha representado una oportunidad estructural de renovación y, con todos sus límites, ha traído algún beneficio -no secundario, pero no irrevocable- a los gobernados. ${ }^{17}$ Quien aspira al éxito electoral y necesita convencer a los electores alimenta la que, con excesivo menosprecio, se llama "demagogia", es decir, el hecho de atender a los intereses de los electores y secundar sus expectativas.

Luciano Canfora lo ha explicado muy bien, describiendo la genealogía del concepto. La demagogia no solo se fundamenta en previsiones de conveniencia. También se puede fundamentar en la solidaridad, en la simpatía, en sentimientos de hermandad. No hay nada más impropio y políticamente orientado que el significado peyorativo que muy a menudo se atribuye al término, y que le atribuyen en especial todos los

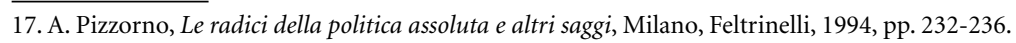


que acusan al régimen representativo-democrático de hacer promesas ilusorias y de adoptar medidas políticas convenientes para los agregados políticos. ${ }^{18}$ No era este el significado originario del término. Al principio, lo que se prometía -y que se hacíapara gratificar al demos podía perjudicar, pero también podía ser útil. ${ }^{19}$ La situación no ha cambiado mucho. La demagogia ha alimentado el racismo, el antisemitismo, la xenofobia. Sin embargo, la demagogia también ha llevado al aumento del sufragio y de los servicios welfare. También las manifestaciones de la demagogia, y de la no demagogia, son hechos políticos.

Aun sin excluir formas espontáneas de protesta, la movilización popular fue promovida sobre todo por los políticos outsiders de la competición política, que planteaban promesas "demagógicas" para lograr el consenso necesario para entrar en el grupo de los contendientes legítimos a la autoridad del Estado. Históricamente, todas las veces que el séquito movilizado por los outsiders ha logrado unos resultados y una fuerza tan grandes como para dificultar la exclusión, los políticos established lo han tenido que aceptar. Es más, algunos de ellos han empezado a emplear la demagogia, a su vez, con promesas y con disposiciones concretas. Con mayor claridad, esto ha llevado a que se enfrenten los que querían que la exclusión permaneciera y los que pensaban que lograrían de los recién llegados consenso electoral y apoyo parlamentario.

El componente octroyée, paternalista, o demagógico del sufragio universal y del welfare fue muy fuerte. El consenso de las clases dirigentes en activo no fue menos relevante que las presiones de los outsiders. En el imperio alemán fue Bismarck -que no era propiamente democrático- quien introdujo ambas cosas. No ocurriría nada de eso si alguien no hubiera enrolado a los ciudadanos contra el orden de las reglas establecidas. La demagogia, estimulada por la exigencia de suscitar el consenso, que caracteriza también a los regímenes autoritarios, y aquella alimentada por los regímenes representativos por la exigencia de enrolar a los electores es lo que le ha permitido al pueblo convertirse en algo más que un abstracto principio de legitimación o un destinatario más o menos complaciente de la acción de gobierno.

Cuando han necesitado del apoyo del pueblo, los que compiten por el poder lo han movilizado, organizado e incluso transformado en sujeto político, o en una pluralidad de sujetos políticos. ${ }^{20}$ Los aspirantes al poder se han convertido en sus portavoces, lo han dirigido a interesarse por la vida política, lo han empujado a que participara en ella, más

18. L. Canfora, Demagogia, Sellerio, Palermo, 1993.

19. El más explícito tal vez sea J. A. Schumpeter, Capitalism, Socialism and Democracy (1943), Routledge, New York-London, 1994.

20. S. Hayat, “La représentation inclusive”, en Raisons politiques, 50, 2013, pp. 115-135. 
o menos activamente. Tal vez le hayan propuesto "metas inalcanzables", ${ }^{21}$ persuadiéndole a creerlo. De esa manera, paradójicamente, no solo el pueblo ha sido movilizado para que se convirtiera en un recurso para la lucha política, sino que también le ha sido otorgada una pequeña -aunque no irrelevante- parte de poder.

Similares efectos de los regímenes representativo-democráticos no han sido planificados de forma consabida y a largo plazo. Además, no todo el mundo los quería. La representación fue inventada más con la intención de legitimar a los representantes que para ayudar a los representados. Quien inventó el régimen representativo no quería ni siquiera que este sirviera para seleccionar a los más capacitados para gobernar. A pesar de eso, desde el principio fue considerado una nueva posibilidad de acceso al poder que -tal y como ha puesto de manifiesto Namier- dio lugar a una terrible aunque no sangrienta lucha por los cargos públicos. ${ }^{22}$

\section{La profesionalización de la política}

Al principio, cuando nació el régimen representativo en Inglaterra, el Parlamento sirvió para consagrar como elite política a la elite social que ya se reunía en el Parlamento y que dominaba a la sociedad. Por lo que al perfil colectivo de la representación esbozado por Lewis Namier para los Comunes hacia mitad del siglo XVIII se refiere, la mayoría de los escaños de Westmister estaba ocupada por personajes notables que, en la competición electoral invertían su patrimonio, su prestigio social, sus relaciones familiares, los servicios de protección y de asistencia que erogaban a sus subordinados y que eran la característica de las relaciones entre notables. A menudo ese capital político se transmitía -junto con el escaño- de forma hereditaria.

Quienes se reunían en los bancos de los Comunes eran los primogénitos de las grandes familias aristocráticas a la espera de llegar a ser Lores y los grandes terratenientes. Era la facción de las clases propietarias del siglo anterior -que se había renovado parcialmente tras la revolución y la restauración- que competía con las nuevas facciones "burguesas" en busca de reconocimiento y de poder. En Westminster, también se hallaban funcionarios, oficiales, almirantes, algunos arribistas y políticos casi profesionales, sobre todo abogados, quienes se servían del prestigio del escaño parlamentario y de las consiguientes relaciones para aumentar su clientela. También había algún protegido de

21. R. Simone, Come la democrazia fallisce, Bompiani, Milano, 2015, p. 40.

22. L. B. Namier, The structure of politics at the accession of George III, MacMillan, Basingstoke, 1957, p. 16. 
la Corona y del Gobierno, quien -tal y como acaecerá más tarde en Francia y en Italiano dudaba en emplear los medios de los que disponía para orientar a su favor la composición de la representación. Para todos, el Parlamento era la posición desde la cual se podían lograr cargos, sinecuras, pensiones, pedidos y financiaciones, además que para negociar cualquier cosa. ${ }^{23}$

Después de la mitad del siglo XVIII, este equilibrio empezó a comprometerse. La sociedad cambiaba. Los que aspiraban al poder aprendieron a aprovecharse de las potencialidades del dispositivo electoral. La actividad de reclutamiento de los electores empezó a sistematizarse, suministrándoles prestaciones materiales y simbólicas. Al mismo tiempo, los electores descubrían - por sí solos y/o con la ayuda de alguien- que el voto era un recurso a cambio del cual podían exigir otras cosas. El tribunal de la opinión -que se desarrolló alrededor del Parlamento- había empezado a analizar críticamente la vida pública y a hacer hincapié en ella, censurando tanto las injerencias de la Corona como las prácticas de patronage con las que los notables enrolaban a sus electores.

Se empezaba a hablar de uno de los argumentos más persistentes y versátiles de la polémica política -la tutela de la moralidad pública y del interés general-, contrastando la presencia constante en política de la autoridad social y de las redes de relaciones personales, junto con la movilización de los intereses. Pensemos en la figura de Burke, contrario tanto a las presiones sobre el voto ejercidas por la Corona y por el ejecutivo como a las presiones de los electores sobre candidatos y elegidos. Se obtuvo un primer resultado con la reducción de la lista civil, limitando la posibilidad de la Corona de condicionar las elecciones. Luego hubo algunas reformas de la administración pública contra las prácticas de patronage que la instrumentalizaban. También los miedos suscitados por la Revolución francesa tuvieron buenos resultados, aunque el más importante a largo plazo fue la reforma electoral de 1832, que renovaría bastante el personal político y sobre todo su composición. ${ }^{24}$

Sin embargo, la más importante e inesperada innovación derivada de la contestabilidad legítima del monopolio estatal fue otra, es decir, el nacimiento de un nuevo y temible competidor por la lucha por el poder. Se trataba de los encargados profesionales de la política electiva. ${ }^{25}$ En palabras de Elias, no todos sabían resolver una contienda con

\footnotetext{
23. Ibid., pp. 158-172.

24. Por lo que al larguísimo camino de la reforma electoral se refiere, cfr. J. Cannon, Parliamentary Reform 1640-1832, Cambridge University Press, Cambridge, 1973.

25. El concepto de "clase política" de Gaetano Mosca no se limita solo a los regímenes representativos. B. Manin, Principes dugouvernement représentatif, habla de "aristocracia electiva".
} 
las palabras, es decir, con la persuasión. ${ }^{26} \mathrm{Ni}$ tampoco todos lograban un séquito electoral. La lucha política exigía que se supiera hablar en público, discutir, negociar, conciliar intereses diferentes, dependiendo del momento, legislar, siempre minimizando los riesgos electorales y evaluando -un político también razona sobre eso- los efectos de largo plazo de su acción.

La hipótesis más frecuente -sostenida por Weber- es que la moderna profesionalización política se ha impuesto gracias a los partidos. ${ }^{27}$ En realidad es un fenómeno anterior. Cuando fue instituido el mercado electoral, aparecieron empresarios que intuyeron una oportunidad de inversión. Reclutar a los electores no era simple, pero sí rentable, incluso con un sufragio restringido. Si se ejercía presión para ampliarlo, también se podían reclutar a los electores potenciales. Para eso surgieron empresas políticas individuales y empresas dotadas de capitales políticos colectivos, es decir, los partidos, capaces de suministrar servicios de protección social a gran escala.

Gracias a la profesionalización política, las facciones que encabezaban el Estado se renovaron y democratizaron mucho, aunque de forma ambigua. El capital colectivo del que disponían los partidos les permitía reclutar a su propio personal en todas las clases sociales. En compensación, la profesionalización y la burocratización produjeron efectos de separación entre los encargados de la política y los electores, convirtiéndose en otro argumento de disputa política. ${ }^{28}$ Sin embargo, lo que no se puede negar es que los partidos, encabezados por encargados profesionales, han sido un dispositivo muy útil para encauzar y reglamentar el pluralismo, aunque complicando los conflictos para el ejercicio del monopolio estatal.

Al principio, por la extracción social común, las burocracias públicas se parecían a los encargados de la política notables. Cuando los encargados de la política se profesionalizaron y su reclutamiento se hizo más democrático, ellos empezaron a necesitar de recursos para sobrevivir -aquellos públicos son más seguros que los privados-y el conflicto para el ejercicio del monopolio estatal se complicó más. De hecho, a la rivalidad entre facciones políticas se añadió la de entre facciones políticas y las burocracias que, mientras tanto, se habían convertido en totalmente profesionales, otorgándoles -gracias

26. N. Elias, The Germans: Power Struggles and the Development of Habitus in the Nineteenth and Twentieth Centuries, Columbia University Press, New York, 1996.

27. M. Weber, E1 político y el científico (1917-1919), El Libro de Bolsillo Alianza Editorial, Madrid, 1979, pp. 81-179; M. Weber, Politik als Beruf (1919), en Id., Gesamtausgabe, W. J. Mommsen, W. Schluchter (hg.), 17, Tübingen, 1992.

28. Con referencia a la burocracia, Max Weber emplea explícitamente el término "casta". Por un lado, la democracia quiere zafarse de la aristocracia y de los notables, y por otra parte, desconfía de la creación de una nueva casta privilegiada, la de los profesionales de la política: cfr. Id., Economía y Sociedad. Esbozo de sociología comprensiva, II, Fondo de Cultura Ecónomica, Madrid, 2002, pp. 251 ss. Cabe referirnos a R. Michels, La sociologia del partito politico nella democrazia moderna. Studi sulle tendenze oligarchice degli aggregati politici, il Mulino, Bologna, 1966. 
a su competencia profesional verificada por medio de un concurso- la tutela del interés general contra las intromisiones centrífugas de las partes políticas. Una vez más, para contingentar la pluralidad derivante de las elecciones, en la segunda mitad del siglo XIX, las facciones que controlaban el monopolio del capital estatal revaluaron y potenciaron la que, entre ellas, había inventado la Razón de Estado, favoreciendo el "interés para el desinterés" ${ }^{29}$ Era inevitable que la burocracia chocara con la pluralidad simplificada, aunque aguerrida, que los partidos de masas transmitían, y solo en la segunda posguerra el problema fue provisionalmente solucionado.

Si, por una parte, es verdad que la sustitución de las luchas violentas para la autoridad estatal por luchas pacíficas caracterizó a los regímenes representativo-democráticos, por otra parte también es verdad que la competencia pacífica para los cargos públicos siempre fue muy dura y nunca demasiado leal, y llevó a veces a efectos devastadores. En palabras de Foucault, la política no es otra cosa que la prosecución de la guerra con otros medios, también en los regímenes representativos. ${ }^{30}$ Es una guerra entre facciones de encargados del Estado, de la competición política, pero también de la economía, de la religión y de otros ámbitos; una guerra, pues, entre instituciones del Estado, como el ejecutivo, el Parlamento, la Magistratura, la Corte Constitucional, las administraciones locales, etcétera. ${ }^{31}$

Las reglas del régimen representativo encauzan, suavizan, pacifican y gobiernan las manifestaciones del pluralismo. Entre los contendores y sus portavoces, que viven por y para el poder, la posibilidad de conquistarlo de forma pacífica aumenta la disposición a negociar. Sin embargo, cabe destacar que también el conflicto pacífico cuenta con unos perdedores y con unas víctimas que sufren las consecuencias. Diríamos que esta es también la condición de los propios regímenes democráticos. Se habla mucho de crisis de la representación y de crisis de los regímenes representativos. En la base de esa reconstrucción, el término crisis está bastante sobredimensionado. Solo estamos observando una nueva oscilación del péndulo. Las técnicas de contingentación del pluralismo se han agudizado. La lucha política ha sacado a luz algunos rasgos de las instituciones oficiales de la representación y también ha multiplicado las formas extraoficiales de representación: las llaman sociedad civil, lobbies y tal vez governance.

29. P. Rosanvallon vuelve a proponer la fórmula de Pierre Bourdieu: cfr. Democratic Legitimacy.

30. M. Foucault, Dits et écrits, II, Gallimard, Paris, 2001, pp. 702-704. En realidad, Foucault se refiere a la política internacional.

31. Está claro que la guerra sigue con medios diferentes también en otros ámbitos: el mercado, la religión, etc. 
Probablemente por eso, quedándose sin portavoces ni representantes, algunas franjas de las poblaciones occidentales estén por debajo del umbral de pobreza, y otros intereses -empresarios, finanzas, entre otros- que han encontrado otras maneras de estar presentes gocen de mayor tutela.

Traducción del italiano de M. Colucciello 